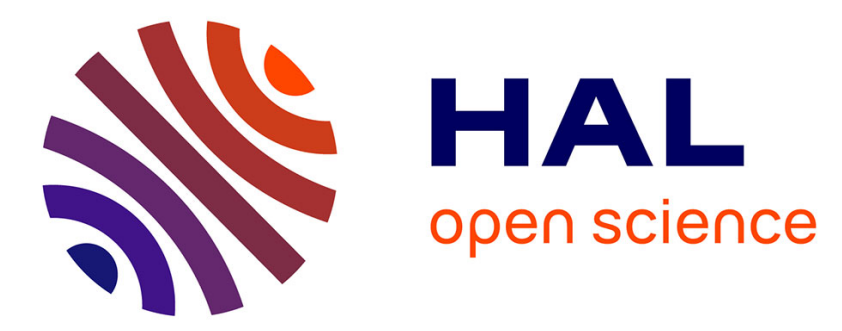

\title{
Proposition of indicators of anthropogenic pressure in the Bay of Toulon (Mediterranean Sea) based on zooplankton time-series
}

B Serranito, Anais Aubert, L Stemmann, N Rossi, Jean-Louis Jamet

\section{- To cite this version:}

B Serranito, Anais Aubert, L Stemmann, N Rossi, Jean-Louis Jamet. Proposition of indicators of anthropogenic pressure in the Bay of Toulon (Mediterranean Sea) based on zooplankton time-series. Continental Shelf Research, 2016, 121, 10.1016/j.csr.2016.01.016 . hal-01328957

\section{HAL Id: hal-01328957 https://hal.science/hal-01328957}

Submitted on 8 Jun 2016

HAL is a multi-disciplinary open access archive for the deposit and dissemination of scientific research documents, whether they are published or not. The documents may come from teaching and research institutions in France or abroad, or from public or private research centers.
L'archive ouverte pluridisciplinaire $\mathbf{H A L}$, est destinée au dépôt et à la diffusion de documents scientifiques de niveau recherche, publiés ou non, émanant des établissements d'enseignement et de recherche français ou étrangers, des laboratoires publics ou privés. 
Research papers

\title{
Proposition of indicators of anthropogenic pressure in the Bay of Toulon (Mediterranean Sea) based on zooplankton time-series
}

\author{
B. Serranito ${ }^{\text {a,* }}$, A. Aubert ${ }^{\text {b,* }}$, L. Stemmann ${ }^{\text {c }}$, N. Rossi ${ }^{\text {d, J.L. Jamet }}{ }^{a}$ \\ a Toulon University, EBMA-PROTEE laboratory E.A. 3819, CS 60584, 83041 Toulon Cedex 9, France \\ ${ }^{\mathrm{b}}$ Aix Marseille Université, CNRS/INSU, IRD, Mediterranean Institute of Oceanography (MIO), UM 110, 13288 Marseille, France \\ ${ }^{\mathrm{c}}$ Université Pierre et Marie Curie-Paris 6, OOV, Laboratoire d'Océanographie de Villefranche (LOV) UMR 7093, Chemin du Lazaret, 06230 Villefranche-sur- \\ Mer, France \\ ${ }^{\mathrm{d}}$ Centre d'Etude et de Valorisation des Algues (CEVA), 22610 Pleubian, France
}

\section{A R T I C L E I N F O}

\section{Article history:}

Received 5 May 2015

Received in revised form

4 January 2016

Accepted 27 January 2016

Available online 28 January 2016

Keywords:

Marine zooplankton

Copepods

Indicators

MSFD

Anthropogenic pressure

GES

\begin{abstract}
A B S T R A C T
Zooplankton present characteristics of high interest in the frame of investigation for organisms sensitive to environmental changes and/or anthropogenic pressures. Such indicators are particularly needed in the present context of European legislation (Marine Strategy Framework Directive). However, zooplankton have not been given the interest they should have in regards to these issues. The aim of the present study is to provide an attempt of proposition of indicators of good environmental status and associated thresholds based on zooplankton data. Zooplankton time-series (2002-2013) from the Toulon Bay in the Mediterranean was used. This time-series presents the great characteristics that the sampling has be done jointly in two areas of the Bay of Toulon known to differ in term of anthropogenic pressures. The study focus on the copepod assemblage and different potential indicators are tested: ratio of copepod families on total copepod and diversity index (Piélou's evenness). The indicators relevance was evaluated per season by looking at the importance of the overlapping region between density's distributions for each indicator in both bays. This methodology well-recognized is commonly used, particularly in the medical sector, for a long time. The results show that the Oithonidae relative abundance and the Piélou's evenness index are the best indicators of anthropogenic pollution for this case study. Thresholds related to the selected indicators are also proposed in order to characterize the degree of anthropogenic pressure for the Toulon Bay and to provide a first evaluation for potential environmental management. Applicability of the selected indicators and future development needed are also discussed. This study is a first step in the investigation for operational zooplankton indicators and should open the way for additional studies in coastal anthropized area such as the Mediterranean coast where it is more urgently needed.

(c) 2016 Elsevier Ltd. All rights reserved.
\end{abstract}

\section{Introduction}

Ecosystems and their natural resources are facing rising challenges in terms of climate change and anthropogenic pressures. Marine ecosystems have been shown to respond rapidly to these environmental changes, especially in coastal areas that are exposed to higher anthropogenic pressures (Beaugrand et al., 2010; Brander, 2010; Burrows et al., 2011). In this context, concern for monitoring and managing the marine environment has strengthen and the European Union included in the Sixth Environmental Action program a commitment to develop a strategy. The EU Marine Strategy Framework Directive (MSFD: 2008/56/EC) is as such the first environmental directive considering the marine

\footnotetext{
* Corresponding authors.

E-mail address: anais.aubert.aa14@gmail.com (A. Aubert).
}

system under an ecosystem approach, thus aiming to link the different marine compartments (biology, physics, chemistry, etc.) in order to maintain the Good Environmental Status (GES) of EU marine waters (Borja et al., 2010). The GES implies that marine resources are used at a sustainable level, ensuring their continuity for future generations. As part of the directive process-steps, the definition and testing of potential relevant tools to monitor the good environmental status is a cornerstone. The concept of "indicator" has been the one identified within the MSFD (Rombouts et al., 2013). An indicator is defined as an evaluation and decision tool which allows to measure a situation or a trend. Such tools permit the link between science and policy decisions and indicators have been documented to be useful for ecosystem management (Niemi and McDonald, 2004).

Literature on diverse type of indicators for the marine system is extensive and these indicators can be based on different groups or species of the marine biota, such as seabirds for instance which 
have been shown to be valuable in order to monitor the ecosystem health (Einoder, 2009). Among potential organisms of interest for marine indicators are zooplankton, however they have been rarely considered in monitoring programs (Perry et al., 2004; Rombouts et al., 2013; Tett et al., 2008). Zooplankton are indeed considered to have a great potential as sentinels of "environmental changes and pressures" (Beaugrand et al., 2010; Legendre, 2005; Richardson, 2008). They are an ecosystemic important component making the link between primary producers and higher trophic levels, in addition to their role in the carbon export to the deep Ocean and nutrients recycling in the upper productive layers (Banse, 1995; Lankov et al., 2010; Urabe et al., 2002). Zooplankton are sensitive to various parameters due to their generally short life cycle. Thus changes at the individual or species level, but also at the scale of community structure, are more likely to happen at a shorter time span compared to higher trophic levels. Also, in contrast to organisms under fishing pressure, zooplankton are not exploited species in Europe, which allows to investigate the environmental pressure impact alone on their fluctuation. In addition they have a large geographical coverage, being consistently present in marine waters all around the world, making potential indicators testable for many areas. It is thus somewhat peculiar that zooplankton had not been prioritized in the first steps of the MSFD process since they present characteristics of high interest in the frame of the directive goals.

The best way to investigate sensitivity of organisms such as zooplankton to environmental and anthropogenic pressures is to consider long-term time-series (Beaugrand et al., 2003; Omori et al., 1994; Perry et al., 2004). Long-term time-series is the only way to actually have an in situ "picture" of the effect of combined pressures on biological communities. To investigate the effect of only one specific pressure would not be accurate since in nature several pressures occurs as a combination, especially in coastal areas (Omori et al., 1994). In the frame of indicator development for policy decisions, there is a need to find general indicators that can be applied in many areas. This involves that the data from which the indicators are calculated need to be comparable. The main issues for data comparability are linked to the sampling and analysis methodology. For station data, representing most of the zooplankton time-series, the $200 \mu \mathrm{m}$ mesh size sampling net is most commonly used. Concerning the taxonomical analysis, it actually depends on the level of determination considered. The species level, the most common considered one in zooplankton community studies, presents limits due to bias linked to the taxonomist knowledge which can be very variable and due to the constant progress made in species determination. Also, if an indicator is based on a specific species, it implies that this specific species needs to be present in the other areas where we want to apply the indicator. Lower levels of taxonomy consider the family, the order or also the functional groups. The bias in taxonomical resolution for these levels is much lower compared to the species one (easier taxonomical recognition). Also since major taxonomic groups exhibit different ecological strategies and traits, and thus represent different functional groups in general, indicators based on these groups can potentially be used to other habitats (Litchman et al., 2013; Waal et al., 2010). To group at a higher level of taxonomy is also in line with the tendency to develop more automatic methodology for monitoring zooplankton and particularly image based analysis. Recent study corroborated the use of family level to investigate the eutrophication impact on the zooplankton community for instance (Carneiro et al., 2013). It is fundamental to assess which level of taxonomical resolution is needed in the frame of zooplankton indicator development. The level of taxonomy required will define the parameters which need to be monitored. It is particularly important to raise these issues and answer them quickly since the monitoring program of the MSFD is building up at the same time of indicator development.

We present here a case study of zooplankton indicator testing based on a long time-series carried out in the Toulon bay on the north-western Mediterranean coast, where zooplankton have been monitored since 1995 (Jamet et al., 2005). Investigation for indicators related to anthropogenic pressures are particularly needed for the Mediterranean basin which represents a hotspot of human impact and a notable high rate of marine species endemism (Coll et al., 2010; Durrieu de Madron et al., 2011). While indicator development is already at a certain stage for northern European countries, due to a better advancement in the national implementation of the MSFD for some of them (England, etc.) and/ or also due to better advancement in northern cooperation (OSPAR, HELCOM), the Mediterranean is late concerning those concerns. In this area more than others, due to the high human pressure and its exponential increase, and thus the greater chance of rapid ecosystem change, the testing of indicator and their development should be clearly emphasized. Also, while several work exist on Mediterranean zooplankton time-series (Berline et al., 2012; Mazzocchi et al., 2007), none of them have actually attempted to develop indicators based on plankton.

The time-series used in this study offers the great opportunity to identify potential indicators of anthropogenic pressure since the monitoring has been done jointly using the exact same methodology for two stations in two neighboring shallow Bays, Little Bay (LiB) and Large Bay (LaB), which are recognized to differ in term of anthropogenic pressures. Different generic indicators of diversity but also ratios of abundances for the zooplankton assemblage are tested. The main aims of the study can be resumed as follow:

- to identify relevant zooplankton indicators of anthropogenic pressures by testing if they reveal significant differences between the two bays over the observed period,

- to define thresholds for the selected indicators which will allow to characterize the level of anthropogenic pressure and a first clear evaluation for potential management decision,

- to discuss on the basis of the results, how to use these indicators, the level of their applicability and the future development needed.

\section{Material and methods}

\subsection{Study site}

Toulon bay (Lat. $43^{\circ} 5^{\prime} \mathrm{N}$ and Long. $6^{\circ} 0^{\prime} \mathrm{E}$ ) is a Mediterranean coastal bay located near Toulon city $(600,000$ inhabitants) characterized by a high level of anthropic activities (Navy harbor, ferry transport, industries, raw sewage). The bay is composed of two sub-bays separated by an artificial breakwater dike: Little Bay (LiB), the most enclosed bay and, Large Bay (LaB) which is an opening on the Mediterranean Sea (Fig. 1). SST ranges between 14.2 and $25^{\circ} \mathrm{C}$ during summer and between 11 and $16{ }^{\circ} \mathrm{C}$ during winter. Salinity ranges between 37.5 and 38.6 through the year. The two bays do not differ significantly in term of temperature and salinity over the annual cycle (personal communication). Due to its location LiB is directly impacted by pollution wastes from the military and commercial harbors and is less affected than LaB by hydrodynamic processes from the offshore. This confers to $\mathrm{LiB}$ a very high contamination in heavy metals like $\mathrm{Hg}, \mathrm{Cu}, \mathrm{Pb}, \mathrm{Zn}$ and some Sn species derived from antifouling painting used for boats (Pougnet et al., 2014; Tessier et al., 2011) but also in Cadmium (Rossi and Jamet, 2008). The zooplankton population in $\mathrm{LiB}$ is characterized by a high abundance and low diversity (Richard and Jamet, 2001; Rossi and Jamet, 2009). Large Bay, which is directly impacted by the Liguro-Provencal current in comparison, presents lower concentration in contaminants and is characterized by a 


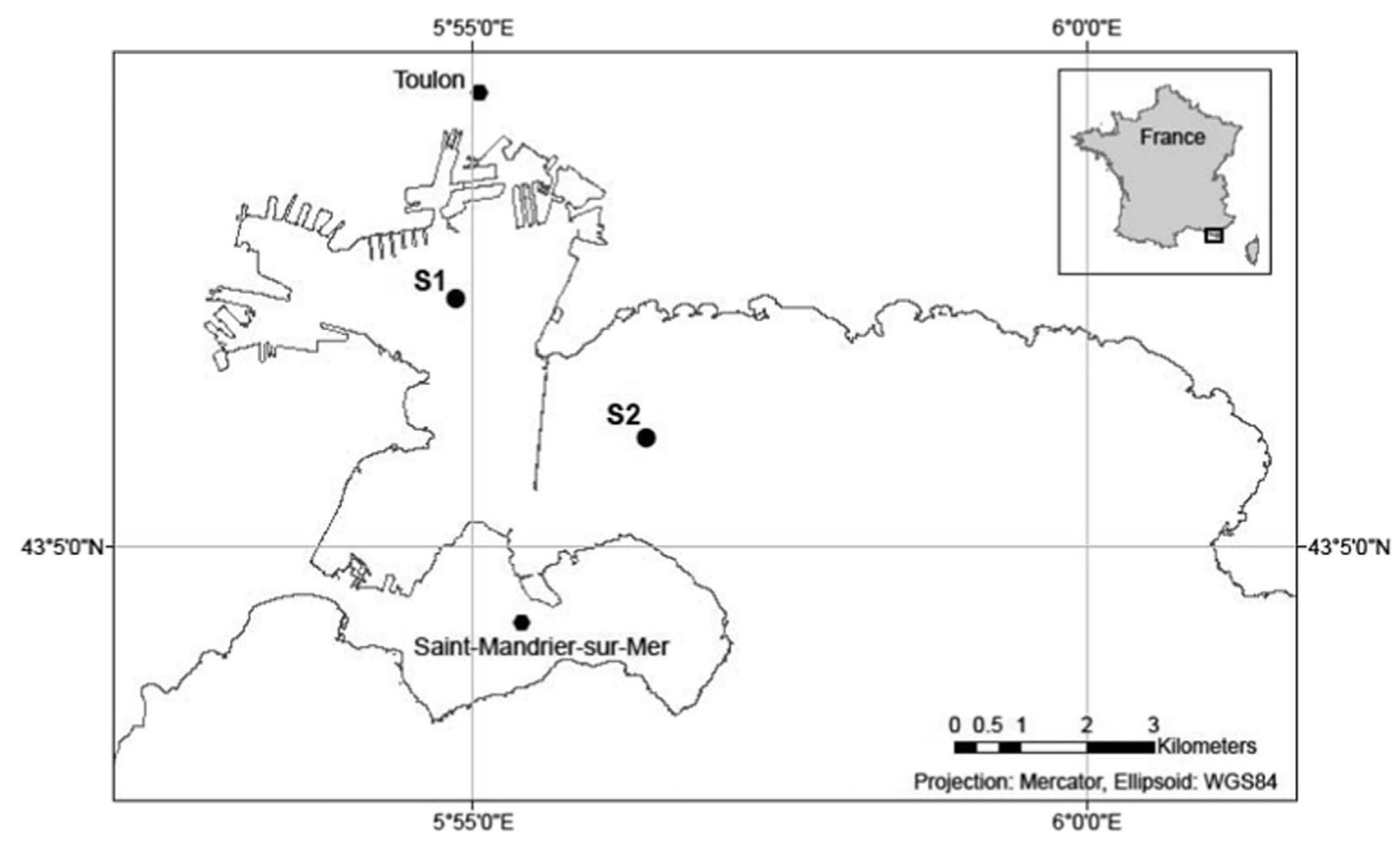

Fig. 1. Localization of the two stations LiB (S1) and LaB (S2) in the Toulon Bay.

higher zooplankton diversity but with lower abundances (Bandeira et al., 2013).

\subsection{Sampling and analysis}

Zooplankton has been monitored at LiB and LaB jointly at a monthly frequency, when possible, since 1995. Quantitative zooplankton samples were obtained using a $90 \mu \mathrm{m}$ mesh size net equipped with a flowmeter deployed vertically from bottom $(10 \mathrm{~m}$ depth for both bays) to surface for both stations. Zooplankton collected in the cod end was preserved with 5\% bufferedformaldehyde. A $250 \mathrm{~mL}$ sub-sample was used for qualitative evaluation in the laboratory. A minimum of 200 organisms contained in $1 \mathrm{~mL}$ of the sub-sample were identified using inverted microscopy. Zooplankton density $\left(D_{z o o}\left(\operatorname{Ind} . \mathrm{m}^{-3}\right)\right)$ was computed as:

$D_{\text {zoo }}=\left(M_{i} . V_{r}\right) / L$

With $M_{i}$ : mean number of individuals counted for the taxa considered, $V_{r}$ : sub-sample volume and $L$ : filtered volume determined with the flowmeter.

In total, 60 different species have been recorded in both bays representing 27 families and 17 orders.

\subsection{Indicators testing}

Zooplankton abundances data were used for the period 20022013 since this period is uniform in term of sampling frequency (some gaps in the years prior to 2002) and in term of level of taxonomic identification. Two types of indicator have been chosen in order to compare the two bays: diversity indicators and relative abundance of taxa. The focus was made only on copepods and on their copepodite stages. Copepods are found in all systems, are a major component of the mesozooplankton biomass and are the most studied zooplankton (Benedetti et al., 2015; Richardson, 2008) which render them particularly relevant in the frame of indicator search that can be tested in different systems. The family being the level chosen to be tested in this study, the most representative copepods families were selected (because rare families are most likely not present in all period and for the two bays, biasing the statistical analysis). Among the 12 copepod families represented and occurring during the study period in the Toulon Bay, 5 families were selected: the Acartiidae (Ac), the Paracalanidae (Par), the Centropagidae (Cent), the Oithonidae (Oith) and the Oncaeidae (Onc). The excluded families which were sporadically represented in the time series were: the Calanidae, the Calocalanidae, the Clausocalanidae, the Coryceaidae, the Ectinosomatidae, the Monstrillidae and the Temoridae. For the copepod families selected, ratios of abundances rather than abundances were computed in order to make the comparison between the two sites. Ratios are used because zooplankton abundances can differ greatly geographically, and thus cannot be used as a proper indicator since it could not be applied to other areas. The indicators were then calculated by month and grouped into season due to the high seasonal pattern of copepod abundance groups well known for the Mediterranean coastal bays (Mazzocchi and d'Alcalà, 1995; Mazzocchi et al., 2011; Rossi and Jamet, 2009). Four seasons were thus determined as: winter (December-February), spring (March-May), summer (June-August) and fall (SeptemberNovember).

Concerning diversity indices, we used the common ShannonWiener index, as follow:

$H^{\prime}=-\sum_{i=1}^{S} f_{i} \log _{2} f_{i}$

where $f_{i}$ is the relative abundance of the $i$ family.

Shannon-Wiener index has been shown to be equivalent with other species richness indicators at the same study site for the zooplankton community (cf. Bandeira et al., 2013). In order to propose threshold values for future potential management, indices such as Piélou's evenness fluctuating between 0 and 1 are preferred. Piélou's evenness $\left(J^{\prime}\right)$ allowing to obtain values of diversity was computed:

$J^{\prime}=\frac{H^{\prime}}{H_{\max }^{\prime}}=\frac{H^{\prime}}{\log 2(S)}$ 
with $H^{\prime}$ : Shannon-Wiener diversity value, $H_{\max }^{\prime}$ : the maximum value of $H^{\prime}$ and $S$ : the total number of family.

\subsection{Statistical analysis}

The relevance of the proposed indicators and their threshold values will depend on their abilities to make the best discrimination between the two bays. First, data normality was tested using a Shapiro-Wilk test at the level of significance $\alpha(\alpha=0.05)$ and indicated that the data were not normally distributed ( $p$-value $<0.05)$. Thus pre-selection of indicators was made with a non-parametric two-sized Mann-Withney $U$-test. The indicators showing a difference between the two bays with a high degree of significance (1\%) were selected (the data from the two bays are considered independent from each other). The null hypothesis $H_{0}$ is verified when $M x=M y$ ( $M=$ Median, $x$ being for data from LiB and $y$ being data from $\mathrm{LaB}$ ) and is rejected when $H 1$ is true. For the selected indicators, the criteria chosen in order to discriminate the two bays was the extent of the overlapping region of their densities. This criteria is commonly used since the 1970s, particularly for medical applications such as discrimination of diagnostic testing (Carpenter and Coustan, 1982; McCane et al., 1994). The values included in the overlapping region are the ones not allowing the discrimination between the two bays in term of anthropogenic pressure while the values out of the overlapping region allow it. Therefore the more this overlapping region is little, the more the indicator is relevant for the specific site studied (LaB and $\mathrm{LiB}$ ).

The evaluation of the overlaps for the selected indicators was realized using non-parametric density probability estimations in order to account for the polymodal nature of the raw data. The density probability function was estimated on log transformed data $\left(X^{\prime}=\log (X+1)\right)$ in order to improve the symmetry of distributions (Legendre and Legendre, 1998) using the following kernel estimator (Silverman, 1986):

$f_{h}(x)=\frac{1}{N h}\left(\sum_{i=1}^{N} K\left(\frac{x-x_{i}}{h}\right)\right)$

where $N$ is the sample size and $h$ the optimal bandwidth of smoothing corresponding to a Gaussian kernel defined as followed:

$K(x)=\frac{1}{\sqrt{2 \pi}} e^{-\frac{1}{2} x^{2}}$

$h=\left(\frac{4 \sigma^{5}}{3 N}\right)^{\frac{1}{5}}$

where $\sigma$ is the standard deviation of the sample.

In order to reduce the overlapping region, a confident region was established applying two unilateral tests with type I error ( $\alpha=10 \%$ ) at the lower and upper bounds of the overlapping region. For each bound, $\alpha$ corresponds to the risk of rejection of $H_{0}$ while it is true, fixing the threshold value $X s 1$ and $X s 2$ (respectively for lower and upper bounds). The Reduced Overlapping Region (ROR) represents values included between these bounds. Associated type II errors ( $\beta 1$ and $\beta 2$ ) represent the risk of the non-rejection of $H_{0}$ while it is false. The degree of distribution overlap was considered as a criterion of indicator relevance. High value of $\beta$ represents low discrimination between the bays (Fig. 2). Each probability is estimated by numerical integration using the following trapezoidal rule:

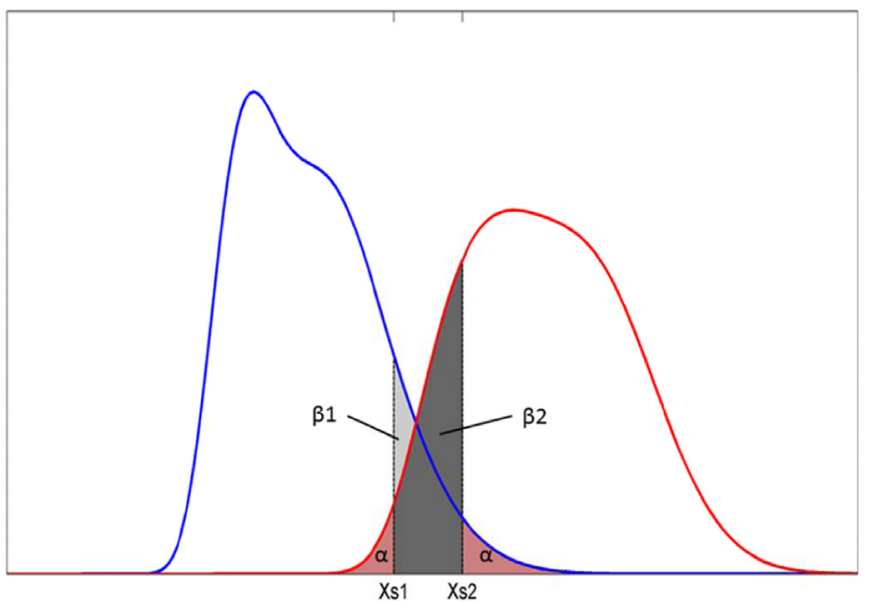

Fig. 2. An example of reduction of the overlapping region between two distributions with the fixed type I error $\alpha$ (red area) characterizing the uncertainty intervals $[X s 1 ; X s 2]$ and the type II errors $(\beta 1$ and $\beta 2)$ associated with the Reduced Overlapping Region (gray area). (For interpretation of the references to color in this figure legend, the reader is referred to the web version of this article.)

$P(a \leq X \leq b)=\int_{a}^{b} f(x) d x \approx \frac{X s 2-X s 1}{2 N} \sum_{n=1}^{N}\left(f\left(x_{n}\right)+f\left(x_{n+1}\right)\right)$

With $x_{n} \in[\mathrm{a} ; \mathrm{b}]$ the modes of an equally spaced grid of size $(N)$

To clarify interpretation from analysis, values related to each bays were grouping into three levels representing different degrees of anthropogenic pressure. Level 1 is only associated with LaB (lower anthropogenic pressure) and Level 3 only with LiB (higher anthropogenic pressure). The level 2 corresponds to the values found both in $\mathrm{LiB}$ and $\mathrm{LaB}$, and thus represents a level of transition.

All statistical analysis were conducted using the Matlab statistical software package.

\section{Results}

For the whole 2002-2013 period, the copepod community was characterized in both bays by a major contribution of the Oithonidae family, the other families being poorly represented (Fig. 3). This was especially true for LiB where the Oithonidae remained the main contributor to total zooplankton abundance through all seasons with higher values during autumn (87\%) and lower ones during spring (72\%). The other families were under-represented in the total abundance in a steady way through seasons $(<3 \%$ for the Paracalanidae, the Oncaeidae and the Centropagidae, and around $8 \%$ for the other copepod families), except for the Acartiidae which showed relative abundance close to those displayed in LaB. In LaB, the family's contributions to total copepod abundance exhibited important seasonal variations, particularly for the Oithonidae which represented between $26 \%$ and up to $67 \%$ of the copepod total mean abundance in winter and summer respectively (46\% for spring and autumn). The Paracalanidae, Acartiidae and Oncaeidae families were well represented during winter (13\%, $6 \%$ and $10 \%$ respectively), spring (9\%,10\% and 5\%) and to a lesser extent during autumn (7\%, 6\% and 2\%). At the exception of spring, the Centropagidae family was the family the less contributing to the total copepod abundance (between $0.3 \%$ and $1 \%$ during winter, summer and autumn). In general the families, except the Oithonidae and the Acartidae, had a much higher contribution to the total copepod abundance in LaB compared to LiB, being between 23\% (summer) and $44 \%$ (winter). 


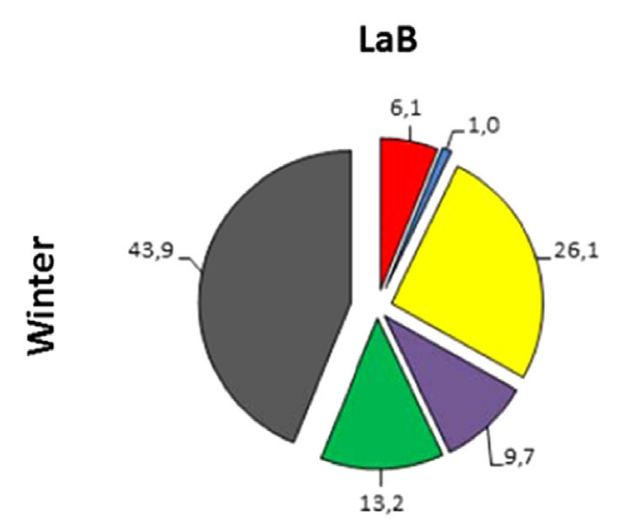

\section{LiB}
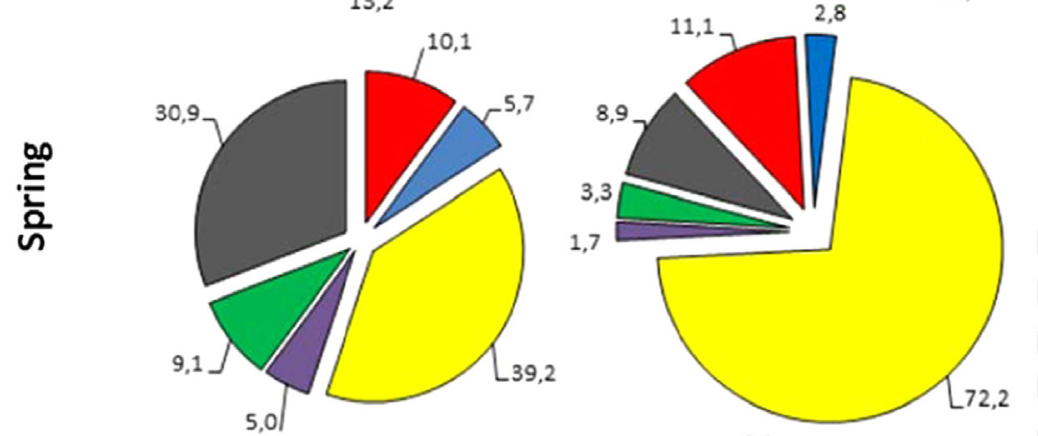

Acartiidae

Centropagidae

Oithonidae

Oncaeidae
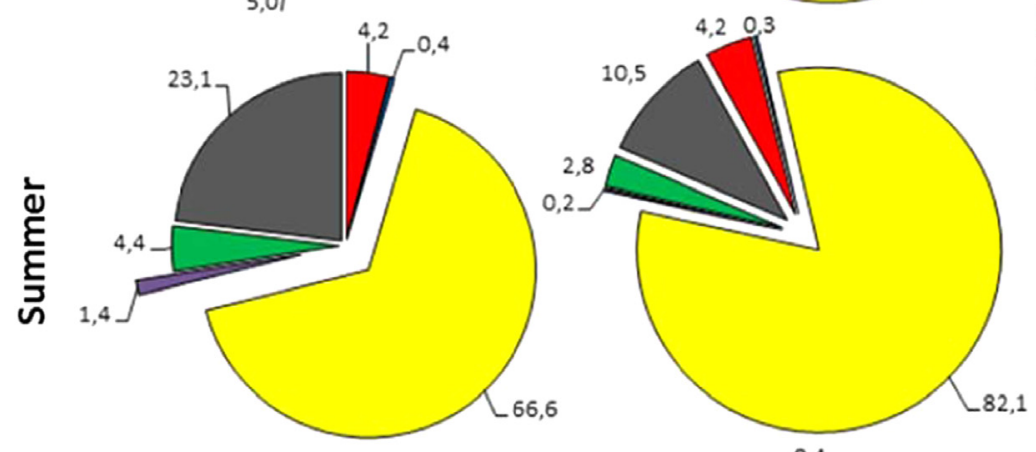

Paracalanidae

Other copepoda
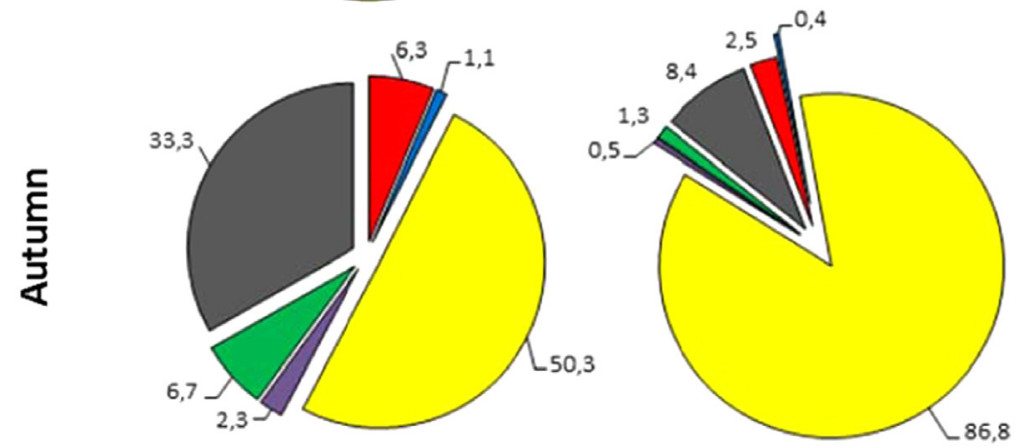

Fig. 3. Copepod families' relative abundances in total copepod abundance for LaB (left) and LiB (right) for each season and expressed in percentages.

The results from the Mann-Whitney $U$ test are summarized in Table 1. Concerning abundances of copepod families in the two bays according to season (Table 1a), the Oithonidae exhibited high differences for all seasons. The Acartiidae abundances also showed differences between the two bays especially during summer and fall ( $p$-value $<0.01)$ and during winter $(p$-value $<0.05)$ (not during spring where $p$-value $>0.05$ ). Except for the Paracalanidae during summer ( $p$-value $<0.05$ ), the abundances of the three other families, the Paracalanidae, the Centropagidae and the Oncaeidae, were not significantly different between the two sites.

Among the 6 indicators considered (5 copepod ratios and Piélou's evenness index), only 4 exhibited high significant differences between the two bays for at least one season ( $p$-value $<0.01$ )
(Table 1b). Among them the Oithonidae indicator and the Piélou's evenness index exhibited differences at a high significant level for all seasons ( $p$-value $<0.01)$. The Oncaeidae indicator exhibited significant differences for winter and the Paracalanidae one for winter, spring and summer ( $p$-value $<0.01$ except during spring where $p$-value $<0.05$ ). Estimation of the probability density function showed a better discrimination between both bays for the Oncaeidae (ROR covering $15 \%$ and $14 \%$ of the LaB and LiB distribution respectively), the Piélou's evenness index (with $7 \%$ and $15 \%$ of LaB and LiB respectively) and particularly for the Oithonidae which exhibited none overlap between the two distributions within the ROR (Fig. 4). The indicators selected for spring were characterized by a large ROR coverage. The Oithonidae one 
Table 1

$P$-values from the Mann-Whitney $U$-test for copepods families abundances (a) and for the relative abundances and indices (b) for each season. Bold value and stars indicate a rejection of the null hypothesis at $5 \%$ and $1 \%$ (respectively indicated as ${ }^{*}$ and ${ }^{* *}$ ).

\begin{tabular}{|c|c|c|c|c|c|c|c|}
\hline a) & \multicolumn{2}{|c|}{ Acartiidae } & \multicolumn{2}{|c|}{ Centropagidae } & Oithonidae & Oncaeidae & Paracalanidae \\
\hline Winter & $0.01^{*}$ & & 0.32 & & 4.64E-10** & 0.15 & 0.66 \\
\hline Spring & 0.11 & & 0.40 & & $2 E-5^{* *}$ & 0.34 & 0.48 \\
\hline Summer & 6.27E-3 & & 0.57 & & $2.62 \mathrm{E}-07^{* *}$ & 0.33 & $0.04^{*}$ \\
\hline Autumn & $6.78 \mathrm{E}-3$ & & 0.31 & & $9.64 \mathrm{E}-11^{* *}$ & 0.67 & 0.62 \\
\hline b) & Acartiidae & Centro & pagidae & Oithonidae & Oncaeidae & Paracalanidae & Pielou's Evenness \\
\hline Winter & 0.41 & 0.24 & & 4.07E-11** & $9 \mathrm{E}-4^{* *}$ & $6 \mathrm{E}-3^{* *}$ & 4.22E-09** \\
\hline Spring & 0.80 & 0.88 & & 2.66E-07** & 0.14 & $0.03^{*}$ & $3.34 \mathrm{E}-06^{* *}$ \\
\hline Summer & 0.92 & 0.63 & & 8.74E-5 ${ }^{* *}$ & 0.20 & 0.45 & $6.03 E-4^{* *}$ \\
\hline Autumn & 0.28 & 0.71 & & 3.79E-06** & 0.92 & $7.29 \mathrm{E}-3^{* *}$ & $5.01 \mathrm{E}-10^{* *}$ \\
\hline
\end{tabular}

described the lowest values of ROR coverage (28\% and 39\% for LaB and LiB respectively). The two other indicators, the Paracalanidae one and the Piélou's evenness index, showed a ROR mean coverage of $50 \%$ of the distribution for $\mathrm{LaB}$, and of $57 \%$ and $36 \%$ respectively for LiB. For summer, the two selected indicators also showed large ROR, with a respective ROR coverage of $41 \%$ and $65 \%$ of the distribution for the Oithonidae and of $68 \%$ and $50 \%$ of the distribution for the Piélou's evenness index for LaB and LiB. During autumn, all the indicators selected exhibited a good discrimination especially for the Oithonidae indicators and the Piélou's evenness index. Their type II errors were low for all seasons with a percentage of overlap less than $16 \%$ for each distribution. The Paracalanidae indicator exhibited a larger overlapping region representing respectively $21 \%$ and $22 \%$ of its $\mathrm{LaB}$ and $\mathrm{LiB}$ distribution.

The threshold ratios for the proposed indicators are presented in Fig. 5. Two groups of indicators related to these thresholds are represented: the ones for which the highest level of anthropogenic pressure (level 3 ) is represented by the highest values (the Oithonidae indicator) and the ones for which this level is represented by the lowest values (the Oncaeidae and the Paracalanidae indicators and the Piélou's evenness index). The values defining the limits of level 2, the transition level, are thus defining is the system is within level 1 or level 3 . For the Oithonidae indicator, the lower values of level 2 ranged between 42.4 and 76.9 (spring and autumn) and the higher ones between 64.3 and 89.3 (winter and summer). For the Oncaeidae indicator in winter, level 2 is bounded between 5.1 and 14.1. For the Paracalanidae indicator, the lower bounds of level 2 ranged between 1.5 and 2.2 (winter and spring) and the higher bounds between 3.9 and 12.1 (autumn and spring). Finally, for the Piélou's evenness index, the lower limit of level 2 ranged between 0.23 and 0.5 (summer and winter) and between 0.41 and 0.64 (autumn and spring) for the upper limit.

\section{Discussion}

\subsection{Relevant zooplankton indicators}

The copepod composition described in the two Toulon bays, characterized by a dominance of Oithonidae, and a small representation of Calanoids, including Acartiidae and Paracalanidae, is characteristic of the zooplankton annual composition found in previous studies in this area (Jamet et al., 2001; Jamet et al., 2005; Rossi and Jamet, 2009). Investigations on zooplankton community in relation to anthropogenic pressure, more specifically to pollution, have been previously run in the Mediterranean (Arfi et al., 1981; Kršinić et al., 2007; Siokou-Frangou and Papathanassiou, 1991; Uriarte and Villate, 2005). In these studies the focus was made at the species level, not the family one, and different species have been shown to present affinity with perturbed systems, particularly the species Acartia clausi, belonging to the Acartiidae. The Acartiidae group was not the dominant copepod group in the present study and did not show any significant difference according to the degree of anthropogenic pressure. The underrepresentation of the Acartiidae might be linked to the fact that a mesh size net of $90 \mu \mathrm{m}$ was used while zooplankton is traditionally sampled with a $200 \mu \mathrm{m}$ mesh size net such as in the studies mentioned. Use of a smaller mesh-size allowed to reveal the strong dominance of Oithonidae, more adequately sampled, and to minimize the presence of the Acartidae. Indeed, the Acartiidae family did not reveal to be a good indicator since this group was quantitatively more important in LiB than in Lab (data not shown), in accordance with a higher total abundance of copepods in LiB, but its relative abundance in the total copepod was the same between the two bays. This indicates that the relative abundance of this group was not influenced by anthropogenic pressure in the Toulon bay.

The Oithonidae was the zooplankton family discriminating the most the two bays, its abundance being much higher in LiB than $\mathrm{LaB}$, as well for its relative abundance on total copepod abundance. This indicates that the Oithonidae seems to be a family with higher affinity with anthropized marine systems and as such, is a potential good indicator of anthropization. While some studies have linked the presence of some Oithonidae species to a small degree of pollution (Etilé et al., 2009; Gubanova and Altukhov, 2007; Webber et al., 2005), other studies from the 70s and 80s from the Marseille area, close to Toulon, have focused on the link between urban pollution and zooplankton communities differences, and have shown the higher quantitative presence of Oithonidae species in relation to a high degree of anthropization (Arfi and Pagano, 1987; Arfi et al., 1981; Champalbert and Patriti, 1982; Patriti, 1972). This was shown despite the fact that they use a mesh size of $200 \mu \mathrm{m}$, thus clearly demonstrating the importance of the Oithonidae species at those locations. Higher abundances of Oithonidae in more anthropized areas have also been put in evidence in a gulf in Greece (where they also conducted a simultaneous sampling in two differently polluted areas) and in an Ivory coast lagoon (Arfi and Pagano, 1987; Moraitou-Apostolopoulou, 1976). In nearly all of these studies, one specific species of Oithonidae was actually associated with a high degree of pollution: Oithona nana. This species has been defined as an euryoecious species such as $A$. clausi. In the Toulon bay, O. nana is the species which actually largely dominates the Oithonidae family all year through with its abundance being much higher in LiB than in LaB (Jamet et al., 2001; Rossi and Jamet, 2009). The present study thus shows that the Oithonidae relative abundance, and more particularly the one of the species $O$. nana, could be used as an indicator of anthropogenic pollution. Higher amount of $O$. nana in areas with a higher anthropized pressure suggest a higher adaptation of this species that can be partly explained by its feeding behavior. It 

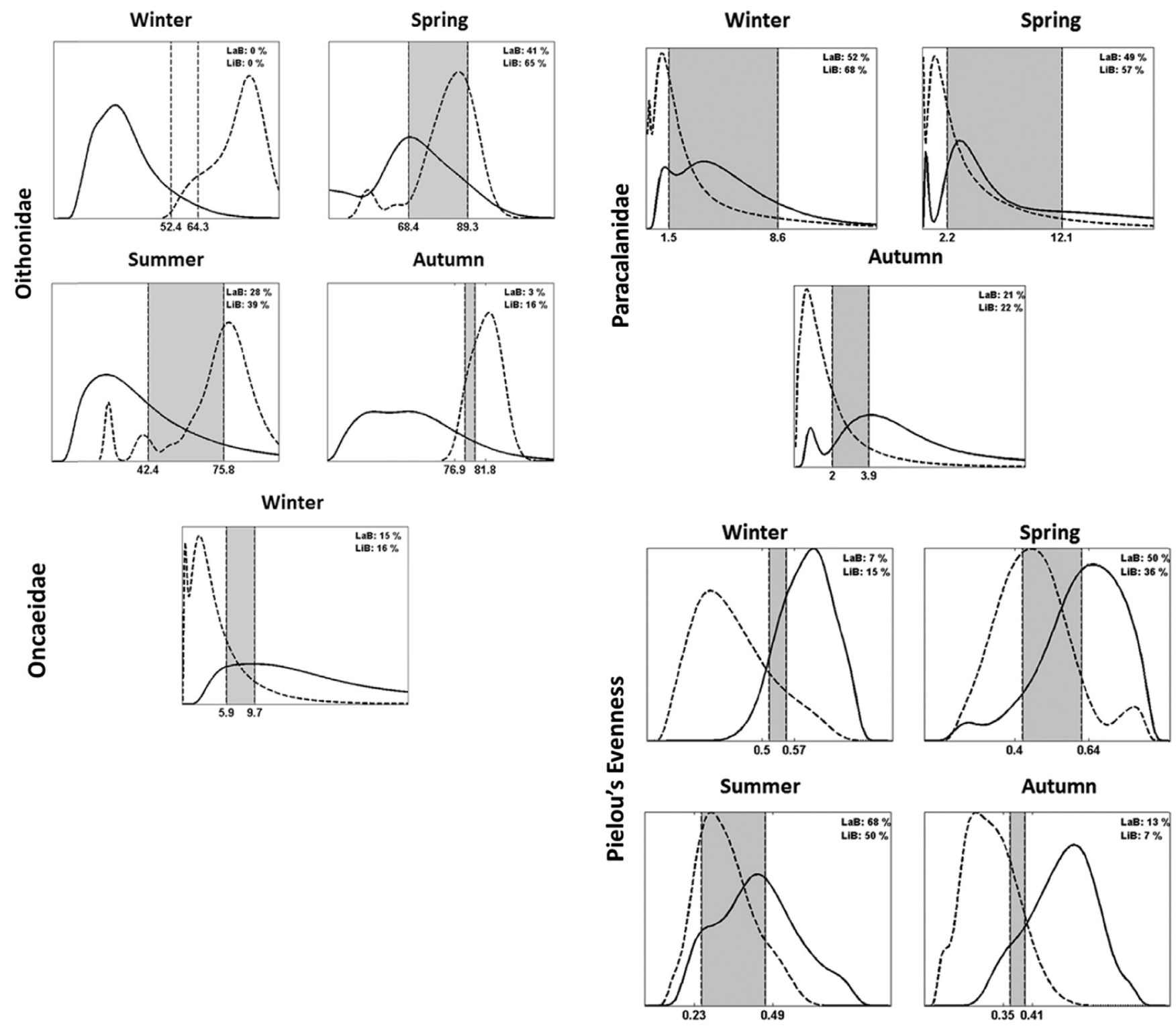

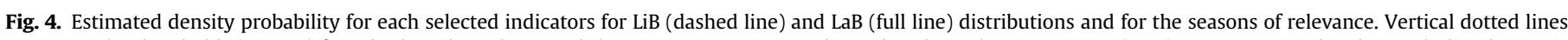

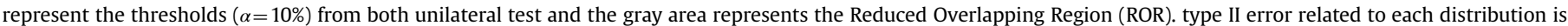
indicated on the top right of each chart.

has been indeed reported to be more flexible in its diet compared to other copepods, thus able to adapt to a wide range of food resources (Lampitt and Gamble, 1982; Moraitou-Apostolopoulou, 1976; Rekik et al., 2012). The shorter life cycle and higher reproduction rate of this small species compared to larger copepods (Gallienne and Robins, 2001) could also partly explain its higher success to adapt to new conditions. Better knowledge of the physiology of this specific species could help to understand its higher adaptation potential and to which degree it is actually able to cope with anthropogenic pressures.

Despite their weak contribution to total copepod abundance, the Paracalanidae and Oncaeidae families showed significant differences in their relative abundances between the two bays for some specific season (during winter for the Oncaeidae and during winter, spring and autumn for the Paracalanidae). Thus they might be considered as indicators of anthropogenic pressure but only for the season specified. Previous pollution impact studies from the Mediterranean showed really different observations for the Paracalanidae type: not influenced by the degree of pollution (Moraitou-Apostolopoulou, 1976), moderately tolerant to pollution (Arfi et al., 1981; Champalbert and Patriti, 1982), associated with the most polluted areas (Arfi and Pagano, 1987) and inversely associated with the less polluted stations (Patriti, 1972). The potential of this species as an indicator should be then considered with caution and more studies should investigate its response to anthropogenic pressure. The Piélou's evenness index seems to be more reliable as an indicator for the whole year through. It followed the trend of the dominant families, and thus reflects the large disparity in the Oithonidae contribution between LaB and LiB. This shows that this type of index can be used in this specific case, where a family relative abundance dominates and is relevant as an indicator. Its use for other cases would require further testing.

\subsection{Operational use of the proposed indicators, limits of applicability and future development needed}

The application of a simple but robust statistical methodology enabled the characterization of the level of anthropization for the selected indicators into three categories. It is important to 

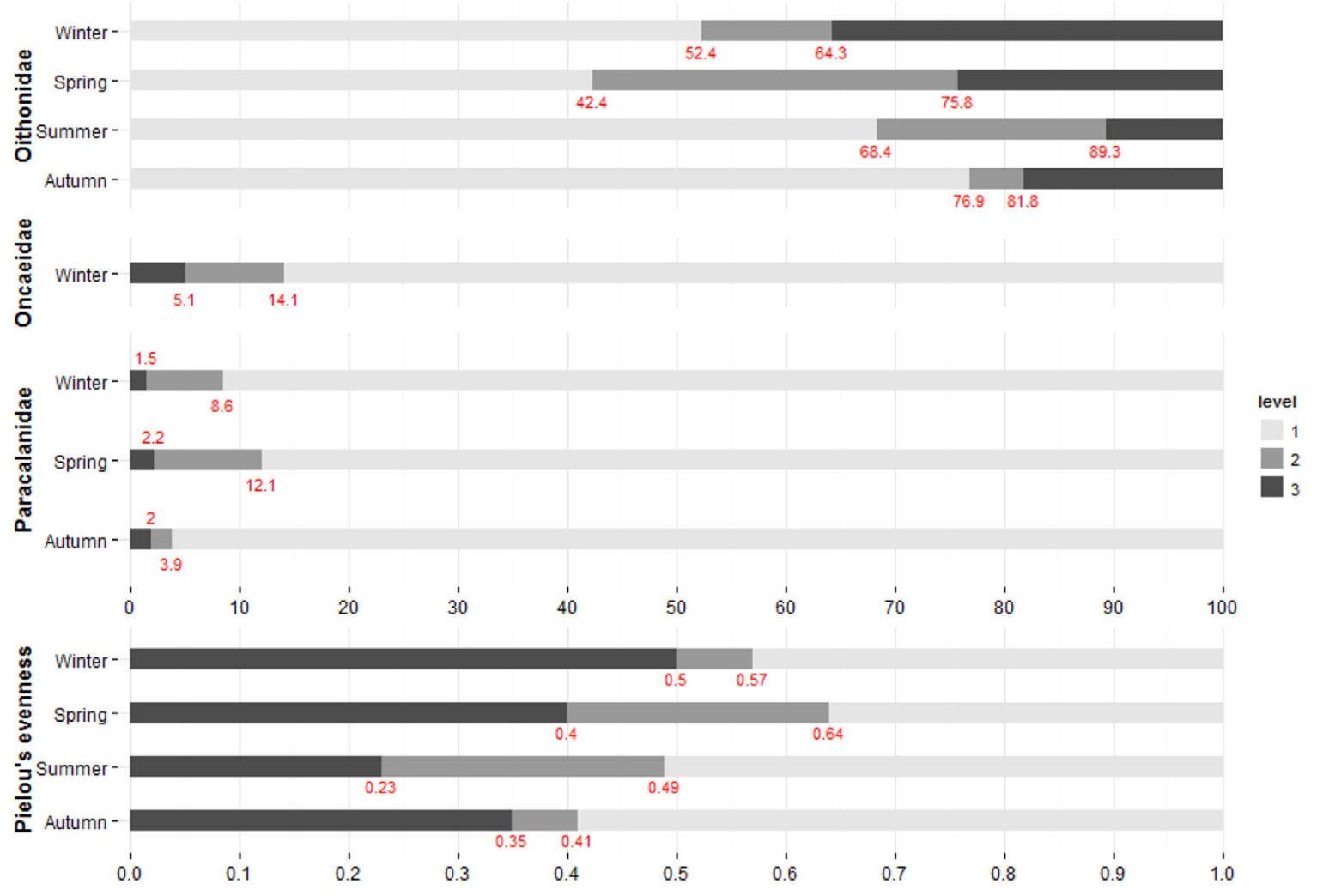

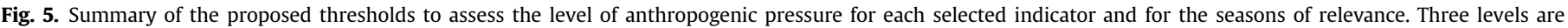

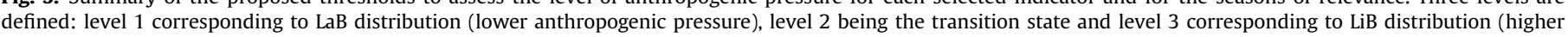
anthropogenic pressure). The values in red are the thresholds values defining the different levels.

highlight that in the frame of investigation for tools allowing to characterize level limits between different states, many approaches from other fields have been developed and are fully operational. The method we used, considering the ROR area, particularly fitted the study case. It is commonly used for a long time in the medical field when the results from a disease test need to be characterized. When these results fall within the overlap distribution area particularly, being then whether false positive or false negative, the choice into one of these categories will have potential important consequences for the later treatment (Carpenter and Coustan, 1982; McCane et al., 1994). As such, and based on this robust methodology, a simple visual figure of the total range of values for each indicator and their correspondence level (as Fig. 5) for the Toulon bays allows a stakeholder in charge of marine management to rapidly level the monitored indicators and to which extent he can use them (particular season, particular taxon). Since LiB represents an ecosystem more anthropized than $\mathrm{LaB}$, the goal of a stakeholder should be to maintain its indicators level as much as possible in level 1 (corresponding to LaB). For the values already in the $\mathrm{LiB}$ state, this will not be possible unless restoration actions are taken. However, restoration of a system does not necessarily implies that the system will return to Level 1 type of zooplankton community (Scheffer et al., 2001). Mesocosms studies testing pollution pressures on zooplankton community shifts could be useful to better understand which parameters drives these shifts and to which extent they occur. The values falling within the transition level are the ones which would actually require the highest attention for environmental management. Indeed, when the indicator of concern is falling within this zone, it indicates that the system (if in LiB) is getting more anthropized and potentially turning to level 3 . It is thus for this level that management actions will be potentially the most efficient in term of "restoration". Testing management actions by decreasing the pollution level is the best way to assess in which way the system will change according to zooplankton composition, and if it will return to level 1. A further step needed that would improve the use of these indicators is to characterize the anthropogenic pressures of the bays. Knowledge about which specific main pollutants and their related amounts actually correspond to the different levels of anthropogenic pressure presented here will allow to know where management actions needs to be taken. It will also render the indicators potentially more usable in other areas, since the level of anthropization could be then compared.

We acknowledge that the selected indicators have to be considered first as local ones, being created for the potential management of the Toulon bay, and might not be applicable to other areas. The zooplankton composition in the Toulon Bay is indeed different from the one described in other eutrophic coastal sites of the Mediterranean (Arfi et al., 1981; Mazzocchi and d'Alcalà, 1995; Siokou-Frangou and Papathanassiou, 1991) and from the generally zooplankton dominance in other seas (Osore et al., 2003; Uriarte and Villate, 2005). However, most zooplankton studies based their sampling on the use of the common $200 \mu \mathrm{m}$ mesh size net (Raybaud et al., 2011; Sameoto et al., 2000) which is known to significantly under-sample the families showing the highest interest in our study, the Oithonidae and the Oncaeidae to a less extent (Gallienne and Robins, 2001). This can explain why the Oithonidae did not appear as important as in the present study for those investigations. Despite this under-representation, many of these studies from the Mediterranean found a link between a high level of anthropization and a high abundance of Oithonidae as mentioned previously. In Arfi and Pagano (1987) they characterized the zooplankton communities' shift due to anthropization in an urban area under marine influence from marine to lagoonal state, the latest state being particularly characterized by the Oithonidae presence. A higher level of anthropization even leaded 
to a community shift toward the dominance of smaller organisms such as rotifers. This shows that higher anthropization pressure can even lead to more drastic changes in the zooplankton composition which can have large impacts on the trophic structure of the system but also on the carbon and nutrient fluxes and recycling processes. Similarities with other areas in the Mediterranean but also with the study from the Ivory Coast indicates that the Oithonidae indicator would be more applicable to other anthropized coastal marine areas than first though. One limit of application of these indicators comes from the use of different mesh size sampling nets, but a conversion factor could be eventually used. It also shows that for really coastal anthropized sites of the Mediterranean, a mesh size net of $90 \mu \mathrm{m}$ should be rather used than the common $200 \mu \mathrm{m}$ one in the frame of the good environmental state monitoring for the MSFD. The fact that the indicators are based on relative abundances rather than abundances of zooplankton is also an important point to consider since really high disparity in abundances exist from one site to another (Berline et al., 2012). A last important issue raised by this study is the level of taxonomy to be considered for zooplankton indicators. Indeed, the goal was to group at a higher level than the species one for a larger applicability of the indicators, and the families being chosen were representative of the north western Mediterranean ecosystem (Razouls et al., 2005-2015). However, the indicator great potential based on one family which is dominated by one specific species challenges this choice. The level to be considered should perhaps rather be the species than the family one. Further investigations taking into consideration both the families of interest and the species level should be run for coastal areas in relation to different anthropogenic pressure level testing. It is really important to make advancement in this field since zooplankton indicators need to be rapidly defined for the MSFD and its monitoring program, which is already building, and so is the definition of the level of taxonomy to follow.

\section{Acknowledgments}

The authors would like to thank S. Richard for her work on copepods determination as well as Mary F. (iSTeP laboratory) for her technical support. Nerini D. is also acknowledged for useful comments on the statistical analysis part. Financial support was provided by PhD grant from "Fond Européen de Développement Régional" (FEDER) and Provence-Alpes-Côte d'Azur (PACA) region in partnership with the Marine National Park of Port-Cros.

This work was also supported by the French Ministery for Ecology, Sustainable Development and Energy (MEDDE) and the French National Centre for Scientific Research (CNRS-INEE).

\section{References}

Arfi, R., Champalbert, G., Patriti, G., 1981. Système planctonique et pollution urbaine: un aspect des populations zooplanctoniques. Mar. Biol. 61, 133-141. http://dx.doi.org/10.1007/BF00386652.

Arfi, R., Pagano, M., 1987. Communautés Zooplanctoniques dans une lagune tropicale (La lagune d'Ebrié, Côte d'Ivoire): variations spatio-temporelles. Hydrobiol. Trop. 20, 21-35.

Bandeira, B., Jamet, J.-L., Jamet, D., Ginoux, J.-M., 2013. Mathematical convergences of biodiversity indices. Ecol. Indic. 29, 522-528. http://dx.doi.org/10.1016/j. ecolind.2013.01.028.

Banse, K., 1995. Zooplankton: pivotal role in the control of ocean production. ICES J. Mar. Sci. . http://dx.doi.org/10.1016/1054-3139(95)80043-3

Beaugrand, G., Brander, K.M., Lindley, J.A., Souissi, S., Reid, P.C., 2003. Plankton effect on cod recruitment in the North Sea. Nature 426, 661-664.

Beaugrand, G., Edwards, M., Legendre, L., 2010. Marine biodiversity, ecosystem functioning, and carbon cycles. Proc. Natl. Acad. Sci. USA 107, 10120-10124. http://dx.doi.org/10.1073/pnas.0913855107.

Benedetti, F., Gasparini, S., Ayata, S.D., 2015. Identifying copepod functional groups from species functional traits. J. Plankton Res. 0, 1-8. http://dx.doi.org/10.1093/ plankt/fbv096.

Berline, L., Siokou-Frangou, I., Marasović, I., Vidjak, O., Fernández de Puelles, M.L., Mazzocchi, M.G., Gorsky, G., 2012. Intercomparison of six Mediterranean zooplankton time series. Prog. Oceanogr. 97-100, 76-91. http://dx.doi.org/10.1016/ j.pocean.2011.11.011.

Borja, A., Elliott, M., Carstensen, J., Heiskanen, A.-S., van de Bund, W., 2010. Marine management - towards an integrated implementation of the European Marine Strategy Framework and the Water Framework Directives. Mar. Pollut. Bull. 60, 2175-2186. http://dx.doi.org/10.1016/j.marpolbul.2010.09.026.

Brander, K., 2010. Impacts of climate change on fisheries. J. Mar. Syst. 79, 389-402. http://dx.doi.org/10.1016/j.jmarsys.2008.12.015.

Burrows, M.T., Schoeman, D.S., Buckley, L.B., Moore, P., Poloczanska, E.S., Brander, K. M., Brown, C., Bruno, J.F., Duarte, C.M., Halpern, B.S., Holding, J., Kappel, C.V., Kiessling, W., O'Connor, M.I., Pandolfi, J.M., Parmesan, C., Schwing, F.B., Sydeman, W.J., Richardson, A.J., 2011. The pace of shifting climate in marine and terrestrial ecosystems. Science 334, 652-655. http://dx.doi.org/10.1126 science.1210288

Champalbert, G., Patriti, G., 1982. Impact de la pollution sur les communautes zooplanctoniques dans la zone d'epandage de l'emissaire urbain de Marseille. Distribution 27, 17-27.

Carneiro, F.M., Nabout, J.C., Vieira, L.C.G., Lodi, S., Bini, L.M., 2013. Higher taxa predict plankton beta-diversity patterns across an eutrophication gradient. Nat. Conservaçao. 11, 43-47. http://dx.doi.org/10.4322/natcon.2013.006.

Carpenter, M.W., Coustan, D.R., 1982. Criteria for screening tests for gestational diabetes. Am. J. Obstet. Gynecol. 144 (7), 768-773.

Coll, M., Piroddi, C., Steenbeek, J., Kaschner, K., Ben Rais Lasram, F., Aguzzi, J., Ballesteros, E., Bianchi, C.N., Corbera, J., Dailianis, T., Danovaro, R., Estrada, M. Froglia, C., Galil, B.S., Gasol, J.M., Gertwagen, R., Gil, J., Guilhaumon, F., KesnerReyes, K., Kitsos, M.-S., Koukouras, A., Lampadariou, N., Laxamana, E., López-Fé de la Cuadra, C.M., Lotze, H.K., Martin, D., Mouillot, D., Oro, D., Raicevich, S., Rius-Barile, J., Saiz-Salinas, J.I., San Vicente, C., Somot, S., Templado, J., Turon, X., Vafidis, D., Villanueva, R., Voultsiadou, E., 2010. The biodiversity of the Mediterranean Sea: estimates, patterns, and threats. PLoS One 5. http://dx.doi.org 10.1371/journal.pone.0011842.

Durrieu de Madron, X., Guieu, C., Sempéré, R., Conan, P., Cossa, D., D'Ortenzio, F., Estournel, C., Gazeau, F., Rabouille, C., Stemmann, L., Bonnet, S., Diaz, F., Koubbi, P., Radakovitch, O., Babin, M., Baklouti, M., Bancon-Montigny, C., Belviso, S. Bensoussan, N., Bonsang, B., Bouloubassi, I., Brunet, C., Cadiou, J.-F., Carlotti, F., Chami, M., Charmasson, S., Charrière, B., Dachs, J., Doxaran, D., Dutay, J.-C., Elbaz-Poulichet, F., Eléaume, M., Eyrolles, F., Fernandez, C., Fowler, S., Francour, P., Gaertner, J.C., Galzin, R., Gasparini, S., Ghiglione, J.-F., Gonzalez, J.-L., Goyet, C., Guidi, L., Guizien, K., Heimbürger, L.-E., Jacquet, S.H.M., Jeffrey, W.H., Joux, F., Le Hir, P., Leblanc, K., Lefèvre, D., Lejeusne, C., Lemé, R., Loÿe-Pilot, M.-D., Mallet, M., Méjanelle, L., Mélin, F., Mellon, C., Mérigot, B., Merle, P.-L., Migon, C., Miller, W.L., Mortier, L., Mostajir, B., Mousseau, L., Moutin, T., Para, J., Pérez, T., Petrenko, A., Poggiale, J.-C., Prieur, L., Pujo-Pay, M., Raimbault, P., Rees, a P., Ridame, C., Rontani, J.-F., Ruiz Pino, D., Sicre, M.A., Taillandier, V., Tamburini, C., Tanaka, T., Taupier-Letage, I., Tedetti, M., Testor, P., Thébault, H., Thouvenin, B., Touratier, F., Tronczynski, J., Ulses, C., Van Wambeke, F., Vantrepotte, V., Vaz, S., Verney, R., 2011. Marine ecosystems' responses to climatic and anthropogenic forcings in the Mediterranean. Prog. Oceanogr. 91, 97-166. http://dx.doi.org/10.1016/j. pocean.2011.02.003.

Einoder, L.D., 2009. A review of the use of seabirds as indicators in fisheries and ecosystem management. Fish. Res. 95, 6-13. http://dx.doi.org/10.1016/j. fishres.2008.09.024.

Etilé, R.N.D., Kouassi, A.M., Aka, M.N.G., Pagano, M., N'Douba, V., Kouassi, N.J., 2009. Spatio-temporal variations of the zooplankton abundance and composition in a West African tropical coastal lagoon (Grand-Lahou, Côte d'Ivoire). Hydrobiologia 624, 171-189. http://dx.doi.org/10.1007/s10750-008-9691-7.

Gallienne, C.P., Robins, D.B., 2001. Is Oithona the most important copepod in the world's oceans? J. Plankton Res. 23, 1421-1432. http://dx.doi.org/10.1093/ plankt/23.12.1421.

Gubanova, A., Altukhov, D., 2007. Establishment of Oithona brevicornis Giesbrecht, 1892 (Copepoda: Cyclopoida) in the Black Sea. Aquat. Invasions 2, 407-410. http://dx.doi.org/10.3391/ai.2007.2.4.10.

Jamet, J.L., Bogé, G., Richard, S., Geneys, C., Jamet, D., 2001. The zooplankton community in bays of Toulon area (northwest Mediterranean Sea, France). Hydrobiol. 457, 155-165.

Jamet, J.L., Jean, N., Bogé, G., Richard, S., Jamet, D., 2005. Plankton succession and assemblage structure in two neighbouring littoral ecosystems in the northwest Mediterranean Sea. Mar. Freshwater Res. 56, 69-83.

Kršinić, F., Bojanić, D., Precali, R., Kraus, R., 2007. Quantitative variability of the copepod assemblages in the northern Adriatic Sea from 1993 to 1997. Estuar. Coast. Shelf S 74, 528-538, http://dx.doi.org/10.1016/j.ecss.2007.05.036.

Lampitt, R.S., Gamble, J.C., 1982. Diet and respiration of the small planktonic marine copepod Oithona nana. Mar. Biol. 66, 185-190. http://dx.doi.org/10.1007/ BF00397192.

Lankov, a, Ojaveer, H., Simm, M., Põllupüü, M., Möllmann, C., 2010. Feeding ecology of pelagic fish species in the Gulf of Riga (Baltic Sea): the importance of changes in the zooplankton community. J. Fish Biol. 77, 2268-2284. http://dx.doi.org/ $10.1111 / j .1095-8649.2010 .02805$.x.

Legendre, L., 2005. Integrating functional diversity, food web processes, and biogeochemical carbon fluxes into a conceptual approach for modeling the upper ocean in a high-CO2 world. J. Geophys. Res. 110, C09S17. http://dx.doi.org/ 10.1029/2004JC002530. 
Legendre, P., Legendre, L., 1998. Numerical Ecology. Elsevier Science, B.V., Amsterdam.

Litchman, E., Ohman, M.D., Kiorboe, T., 2013. Trait-based approaches to zooplankton communities. J. Plankton Res. 35, 473-484. http://dx.doi.org/10.1093/ plankt/fbt019.

Mazzocchi, M.G., d'Alcalà, M.R., 1995. Recurrent patterns in zooplankton structure and succession in a variable coastal environment. ICES J. Mar. Sci. : J. du Conseil 52, 679-691.

Mazzocchi, M.G., Christou, E.D., Capua, I. Di, Fernández de Puelles, M., FondaUmani, S., Molinero, J.C., Siokou-Frangou, I., 2007. Temporal variability of Centropages typicus in the Mediterranean Sea over seasonal-to-decadal scales. Prog. Oceanogr. 72, 214-232. http://dx.doi.org/10.1016/j.pocean.2007.01.004.

Mazzocchi, M.G., Licandro, P., Dubroca, L., Di Capua, I., Saggiomo, V., 2011. Zooplankton associations in a Mediterranean long-term time-series. J. Plankton. Res. 33, 1163-1181. http://dx.doi.org/10.1093/plankt/fbr017.

McCane, D.R., Hanson, R.L., Charles, M.A., Jacobsson, L.T.H., Pettitt, D.D., Bennett, P. H., 1994. Comparison of tests for glycated haemoglobin and fasting and two hour plasma glucose concentrations as diagnostic methods for diabetes. Br. Med. J. 1 308, 1323-1328.

Moraitou-Apostolopoulou, M., 1976. Étude comparative du zooplancton superficiel $(0-100 \mathrm{~cm})$ à un zone hautement polluée et une autre relativement propre (golfe Saronique-Grèce). Rapp. P. V. Reun. Cons. Int. Explor. Mer Medit. 23, 59-60.

Niemi, G.J., McDonald, M.E., 2004. Application of ecological indicators. Annu. Rev. Ecol. Evol. Syst. 35, 89-111. http://dx.doi.org/10.1146/annurev. ecolsys.35.112202.130132.

Omori, M., Van Der Spoel, S., Norman, C.P., 1994. Impact of human activities on pelagic biogeography. Prog. Oceanog. 34, 211-219.

Osore, M., Fiers, F., Daro, M.H., 2003. Copepod composition, abundance and diversity in Makupa Creek, Mombasa, Kenya. Western Indian Ocean J. Mar. Sci. 2, 65-73.

Patriti, G., 1972. Etude préliminaire des effets de la pollution globale sur le peuplement planctonique des ports Nord de Marseille. Mar. Biol. 12, 300-308.

Perry, R., Batchelder, H., Mackas, D., Chiba, S., Durbin, E., Greve, W., Verheye, H., 2004. Identifying global synchronies in marine zooplankton populations: issues and opportunities. ICES J. Mar. Sci. 61, 445-456. http://dx.doi.org/10.1016/j. icesjms.2004.03.022.

Pougnet, F., Schäfer, J., Dutruch, L., Garnier, C., Tessier, E., Dang, D.H., Lanceleur, L., Mullot, J.-U., Lenoble, V., Blanc, G., 2014. Sources and historical record of tin and butyl-tin species in a Mediterranean bay (Toulon Bay, France). Environ. Sci. Pollut. Res. 21, 6640-6651. http://dx.doi.org/10.1007/s11356-014-2576-6.

Raybaud, V., Heroin, D., Raud, T., Brylinski, J.-M, Stemmann, L., Sautour, B., 2011. Census and analysis of zooplankton metadata of the French coasts since 1955. JORD 4, 11-37.

Razouls, C., de Bovée, F., Kouwenberg, J. et Desreumaux, N., 2005-2015. Diversity and Geographic Distribution of Marine Planktonic Copepods. Available at 〈http://copepodes.obs-banyuls.fr/en〉.

Rekik, A., Drira, Z., Guermazi, W., Elloumi, J., Maalej, S., Aleya, L., Ayadi, H., 2012. Impacts of an uncontrolled phosphogypsum dumpsite on summer distribution of phytoplankton, copepods and ciliates in relation to abiotic variables along the near-shore of the southwestern Mediterranean coast. Mar. Pollut. Bull. 64 336-346. http://dx.doi.org/10.1016/j.marpolbul.2011.11.005.

Richard, S., Jamet, J., 2001. An unusual distribution of Oithona nana GIESBRECHT (1892) (Crustacea : Cyclopoida ) in a Bay : the case of Toulon Bay (France, Mediterranean Sea). J. Coast. Res. 17, 957-963.

Richardson, A.J., 2008. In hot water : zooplankton and climate change. ICES. J. Mar. Sci. 65, 279-295.

Rombouts, I., Beaugrand, G., Artigas, L.F., Dauvin, J.-C., Gevaert, F., Goberville, E., Kopp, D., Lefebvre, S., Luczak, C., Spilmont, N., Travers-Trolet, M., Villanueva, M C., Kirby, R.R., 2013. Evaluating marine ecosystem health: case studies of indicators using direct observations and modelling methods. Ecol. Indic. 24 353-365. http://dx.doi.org/10.1016/j.ecolind.2012.07.001.

Rossi, N., Jamet, J.L., 2008. In situ heavy metals (copper, lead and cadmium) in different plankton compartments and suspended particulate matter in two coupled Mediterranean coastal ecosystems (Toulon Bay, France). Mar. Pollut. Bull. 56, 1862-1870.

Rossi, N., Jamet, J.L., 2009. Structure and succession of plankton communities in two Mediterranean Neighbouring coastal ecosystems (Toulon Bays, France). New oceanography research development. Nova Sci. Publ. 11, 1-14.

Sameoto, D., Wiebe., P.H., Runge, J., Postel, L., Dunn, J., Miller, C., Coombs, S., 2000 Collecting zooplankton. In: Harris, R.P., Wiebe, P.H., Lenz, J., Skjoldal, H.R., Huntley, M. (Eds.), ICES Zooplankton Methodology Manual. Academic Press, San Diego 684 pp.

Scheffer, M., Carpenter, S., Foley, J.A., Folke, C., Walker, B., 2001. Catastrophic shifts in ecosystems. Nature 413, 591-596.

Silverman, B.,W., 1986. Density Estimation for Statistics and Data Analysis. Monographs on Statistics and Applied Probability. Chapman and Hall, London.

Siokou-Frangou, I., Papathanassiou, E., 1991. Differentiation of zooplankton populations in a polluted area. Mar. Ecol. Prog. Ser. 76, 41-51.

Tessier, E., Garnier, C., Mullot, J.-U., Lenoble, V., Arnaud, M., Raynaud, M., Mounier S., 2011. Study of the spatial and historical distribution of sediment inorganic contamination in the Toulon bay (France). Mar. Pollut. Bull. 62, 2075-2086. http://dx.doi.org/10.1016/j.marpolbul.2011.07.022.

Tett, P., Carreira, C., Mills, D.K., Leeuwen, S., Van, S., Foden, J., Bresnan, E., Gowen, R. J., 2008. Use of a phytoplankton community index to assess the health of coastal waters. ICES. J. Mar. Sci. 65, 1475-1482.

Urabe, J., Elser, J.J., Kyle, M., Yoshida, T., Sekino, T., Kawabata, Z., 2002. Herbivorous animals can mitigate unfavourable ratios of energy and material supplies by enhancing nutrient recycling. Ecol. Lett. 5, 177-185. http://dx.doi.org/10.1046/ j.1461-0248.2002.00303.x.

Uriarte, I., Villate, F., 2005. Effects of pollution on zooplankton abundance and distribution in two estuaries of the Basque coast (Bay of Biscay). Mar. Pollut. Bull. 49, 220-228. http://dx.doi.org/10.1016/j.marpolbul.2004.02.010.

Van De Waal, D.B., Verschoor, A.M., Verspagen, J.M.H., Van, E., Donk, E. Van, 2010 Climate-driven changes in the ecological stoichiometry pf aquatic ecosystems. Front. Ecol. Environ. 8, 145-152.

Webber, M., Edwards-Myers, E., Campbell, C., Webber, D., 2005. Phytoplankton and zooplankton as indicators of water quality in Discovery Bay, Jamaica. Hydrobiologia 545, 177-193. http://dx.doi.org/10.1007/s10750-005-2676-x. 